\title{
$N$-Benzyloxycarbonyl-2-methylaminothiazoline as a Selective Benzyloxycarbonylating Reagent of Amines
}

\author{
Taek Hyeon Kim ${ }^{*}$ and Jong Chul Chun \\ Deparment of Applied Chemistry, College of Engineering, Chonnam National Chiversitw. Gwangju 500-757, Korea \\ Received October 1, 2002
}

Key Words : $\mathrm{N}$-Benzy'loxycarbonỵl-2-methỵ laminothiazoline. Benẓ̧'loxycarbonylation. Amines

Chemoselective alkoxycarbonylation of amines is an important reaction for the protection in organic synthesis. ${ }^{1} \mathrm{~A}$ variety of reagents have been developed by devising a leaving group such as chlorides. ${ }^{2}$ imidazole. ${ }^{3}$ inide. ${ }^{4}$ oxime. ${ }^{3}$ enolate. ${ }^{6}$ and $N$-sulfonylanilide. ${ }^{7}$ Each method has its advantages and disadvantages in any given situation. Thus the development of other reagents is necessary. Recently, we reported synthetic route to 2-methylaminothiazolines by the selective S-cyclization of $N$-(2-lyydroxyethyl)- $N^{\prime}$-methylthioureas. ${ }^{8}$ Heterocyclic system of 2-methylaminothiazoline 1 is expected to be a good leaving group for alkoxycarbonylation reagent of amines. In this paper we report that $N$ benzyloxy and $N$-tent-butoxycarbonyl-2-methylaninothiazoline $\mathbf{2}$ serve as new reagents for the selective alkoxycarbony lation of a less hindered amines in the presence of a more hindered amines.

The synthesis of 4.4-dimethyl-2-methylaminothiazoline was readily performed by the reaction of 1,2-aminoalcohol with methyl isothiocyanate to give the corresponding $N-(1,1$ dimethylamino-2-lydroxy)ethyl- $N^{\prime}$-methylthiourea. followed by the S-cyclization to the 2-methylaminothiazoline in $83 \%$ yield by a one pot reaction using $p$-toluenesulfonyl chloride and $\mathrm{NaOH}$ (Scheme 1). Acylation of the 2-methylaminothiazolines can conceivably proceed through an attack upon acyl halide either by the exo-nitrgen to provide $N$ acylated-2-methylaninothiazolines or by the endo-nitrgon to

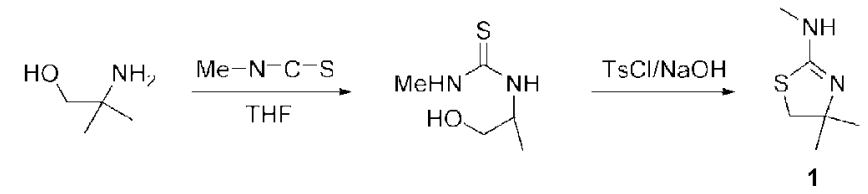

Scheme 1
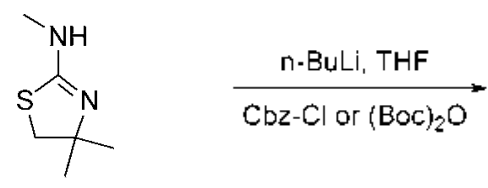

1

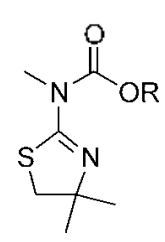

$2 \mathrm{a}, \mathrm{R}=\mathrm{Bn}$

2b, $\mathrm{R}=$ tert $-\mathrm{Bu}$

Scheme 2 give $\mathrm{N}$-acylated 2-methyliminothiazolidine. ${ }^{11 j}$ Alkoxycarbonylation of thiazolines 1 with benzyloxycarbony chloride $(\mathrm{CbzCl})$ and tert-butoxycarbonyl chloride $(\mathrm{BocCl})$ under $n$ BuLi gave only the $N$-benzyloxy and $N$-tert-butoxycarbonyl2-methylaminothiazoline 2 (Scheme 2). After column chromatograply. $\mathbf{2 a}$ and $\mathbf{2 b}$ were obtained as air storable oil in $96 \%$ and $93 \%$ yields. respectively. ${ }^{11}$

We next turned to our attention to the $\mathrm{N}$-alkoxycarbonyl transfer potentiality of $\mathbf{2}$ to amine. Benzyloxycarbonylation of bezylamine with $2 \mathrm{a}$ was examined first in a variety of solvents such as THF, $\mathrm{CCl}_{4}$, and $\mathrm{EtOH}$. No reaction occurred in refluxing THF and $\mathrm{CCl}_{4}$ for $40 \mathrm{~h}$. Even treatment of benzylamine with $n-\mathrm{BuLi}$ in THF to enhance the nucleoplilicity of amine did not provide the desired carbamate. In refluxing ethanol, primary and secondary amines gave the corresponding carbamate in good yields (Table 1 , entries 1-3). However. the reaction time required for the completion depended on

Table 1. Synthesis of $\mathrm{Cbz}$ - and Boc-amine with $\mathbf{2 a}$ and $\mathbf{2 b}$

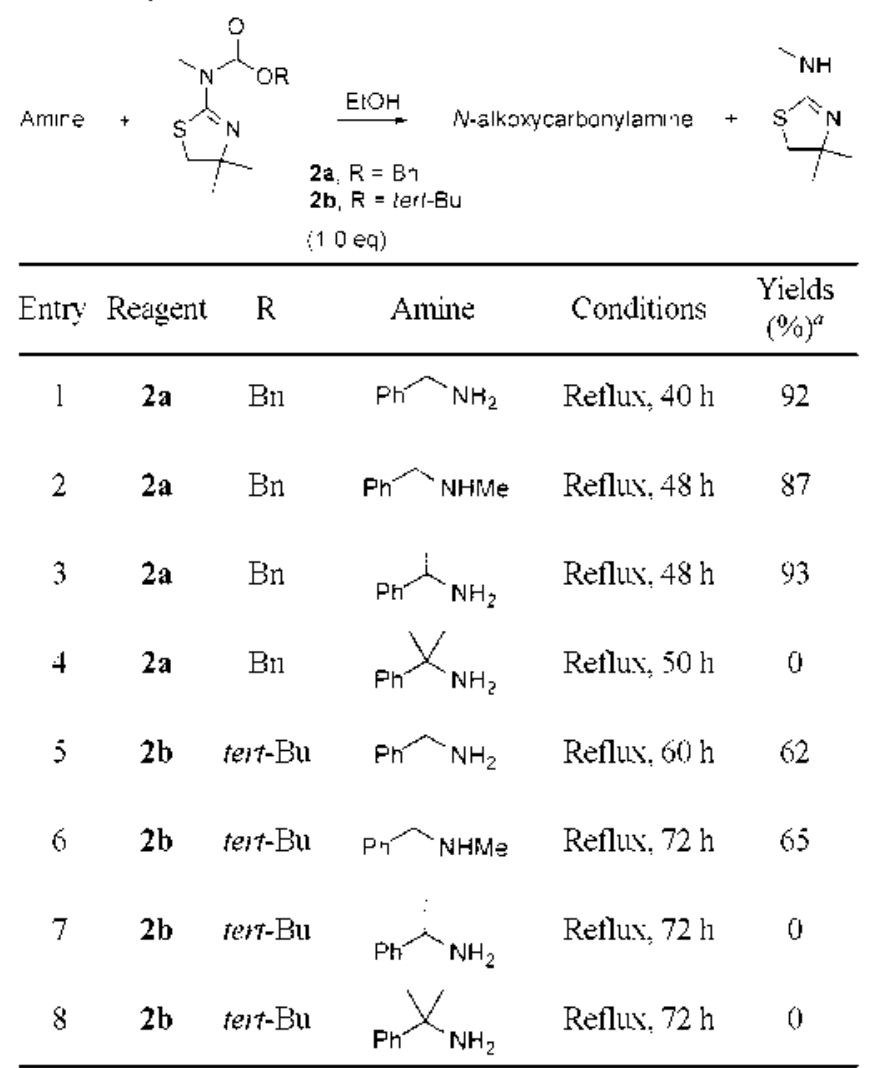

Isolated yield by column chromatography 
Table 2. Competitive alkoxycarbonylation

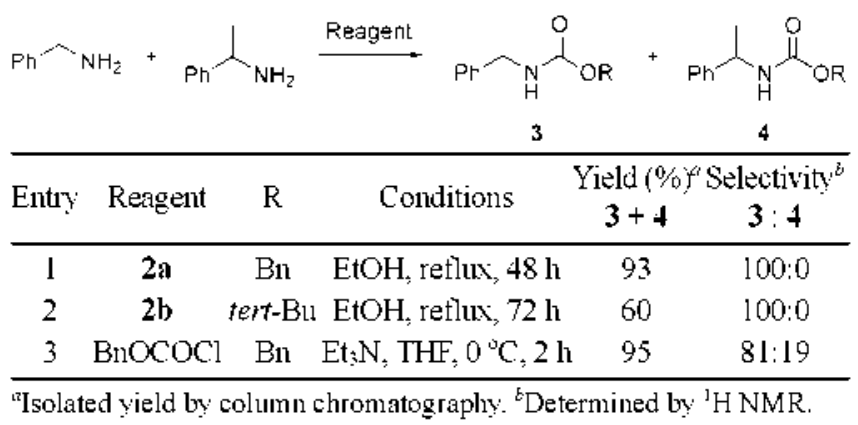

the bulkiness of amine. Very sterically hindered cumylamine did not yield Cbz-derivative in reflux for $50 \mathrm{~h}$ (Table 1, entry 4). Under the same conditions using $\mathbf{2 b}$, benzylamine and $N$ methylbenzylamine were converted to the Boc-derivatives in $86 \%$ and $85 \%$ yields. respectively. Hindered alkyl amines were not acylated even in refluxing EtOH for $72 \mathrm{~h}$ (Table 1. entries 7-8). These differences in reactivity between Cbzand $\mathrm{Boc}$-derivatives are due to the efficient bulkiness around the carbonyl group of $\mathbf{2 b}$ by the tert-butoxy groups. indicating the reactivity of $\mathbf{2 b}$ is more sensitive to the steric hinderence of the amines. The leaving group, 2-methy laminothiazoline 1 was almost quantitatively recovered for recycling sumply by extracting with acidic aqueous solution. After washing. concentration of organic layer gave the crude alkoxycarbonylated product. which was purified by column chromatography or recrystallization. Comparison of the crude reaction product in each case was made with authentic samples of the possible carbamate product using NMR spectroscopy. ${ }^{1 \Sigma}$ The substantial difference in reaction rate between hindered and less hindered anines prompted us to examine selective acylation of amines. We chose to investigate the selectivity in the acylation of a $1: 1$ mixture of a hindered primary amine and a less hindered primary anine with $\mathbf{2}$. The results are summarized in Table 2. With both $\mathbf{2 a}$ and $2 \mathrm{~b}$ high selectivity was observed. Benzyloxycarbonylation of the common reagent. $\mathrm{BnOCOCl}$ obviously gave a worse selectivity compared with the same reaction using $\mathbf{2 a}$ (Table 2, entry 3). To test the above selective benzyloxycarbonylation in diamines by $\mathbf{2 a}$ a benzy loxycarbonylation of $N$-propylethylene diamine and 2-methylpiperizine were performed to afford the mono-Cbz-derivatives ( 5 and 6 ) in $98 \%$ and $93 \%$ yields. respectively. which were only acylated product at the less hindered nitrogen (Scheme 3).

In conclusion $N$-benzyloxycarbonylated 2-methylaminothiazoline is very effective in selective $N$-benzyloxycarbonylation of amines. We believe that this novel benzyloxy-

$$
\text { 㧒 }
$$

Scheme 3 carbonylating agent can be widely used for the selective protection of various polyamine compounds. The further development as a general acylating agent is in progress.

Acknowledgment. This work was supported by the grant No. (R05-2002-000-00043-0) from the Basic Research Program of the Korea Science and Engineering Foundation.

\section{References}

1. Greene. T. W. Wuts, P. G. M. Protective Ghotp in Organic Smithesis, John Willey and Sons, Ine: New York, 1991: 503.

2. Atwell. G. J.: Denny, W. A. Synthesis 1984, 1032.

3. Shama. S. K.: Miller. M. T.: Payne. S. M. J.1 fed. Chem. 1989. 32. 357.

4. Henklein1. P.: Heyne. H.-U.: Halatsch. W.-R.: Niedrich. H Simhesis 1987. 166.

5. Itoh. M.: Hagiwara, D; Kamiya, T. Bull. Chent. Soc. Jpm 1977. 50.718 .

6. Kita. Y.: Haruta. J.: Yasuda. H.: Fujuraga. K.: Shirouchi. Y.: Tamura. Y. J. Org. Chem. 1982. 47. 2697.

7. Kondo. K.: Sekimoto. E.: Miki. K.: Murakami. Y. J. Chent Soc. Perkin Trans. 1 1998. 2973.

8. Kim. T. H: Cha. M.-H. Tetrohedron Lett. 1999. 40. 3125.

9. Synthesis of 4.5-Dihydro-4,4-dimethyl- $N$-methy-2-thiazolamine 1. To a stimed solution of $k-[(1.1-$ dimethyl-2-hydrosy $)$ ethyl]- $x$ methylthiourea $(3.01 \mathrm{~g} .19 \mathrm{mmol})$ in $\mathrm{THF}(20 \mathrm{~mL})$ under nitrogen at room temperature was added a solution of $\mathrm{NaOH}(0.76 \mathrm{~g} .2 .2$ mmol. $250 \mathrm{M}^{\circ} \cdot 0$ ) in water ( $5 \mathrm{~mL}$ ) and TsCl (3.89 g. mmol. 110 $\mathrm{M}^{\circ} \%$ ) in THF (5 $\mathrm{mL}$ ) dropwise for $5 \mathrm{~min}$ with a syringe. The reaction mixture was stirred for $30 \mathrm{~min}$ at room temperature. quenched with water $(30 \mathrm{~mL})$. and extracted with ether $(30 \mathrm{~mL} \times$ 3). The organic layer was dried. filtered. and concentrated to give the crude product. which was purified by tlash column chromatography to give the eyclized product $1\left(2.3 \mathrm{~g}, 83^{\circ}\right.$ o vield). White solid. $\mathrm{mp} 105-107^{\circ} \mathrm{C}: R_{f}=0.1$ (ethyl acetate): 'H $\mathrm{HMR}(300$ $\mathrm{MHz} . \mathrm{CDCl}_{3}$ ) $\delta 3.26$ (s. $2 \mathrm{H} . \mathrm{SCH}_{2}$ ). 2.94 (s. $3 \mathrm{H} . \mathrm{NCH}_{3}$ ). 1.42 (s. $\left.6 \mathrm{H} .2 \mathrm{CH}_{3}\right)$. ${ }^{\mathrm{C}} \mathrm{NMR}\left(75 \mathrm{MHz} . \mathrm{CDCl}_{3}\right) \delta 159.4 .73 .1 .46 .2$. 31.4. 28.3. Anal Caled for $\mathrm{C}_{6} \mathrm{H}_{12} \mathrm{~N}_{2} \mathrm{~S}:$ C. 49.96: H. 8.39: N. 19.42: S. 22.23. Found: C. 51.22: H. 8.51: N. 18.93: S. 22.60. This method was more efficient in purification, compared to our previous work using Mitsunobu reaction (DEAD and triphenyl phosphine). ${ }^{8}$

10. Argay. G.: Kalman. A.: Toth, G.; Toldy, L. Tetohedron Lett. 1972. 3179 .

11. Synthesis of Berzyl N-(4.5-dihydro-4.4-dimethyl-2-thiazolyl) - Nmethylcarbamate 2a. To a stirred solution of $1(0.51 \mathrm{~g} .3 .54 \mathrm{mmol})$ in dry THF (20 mL) under nitrogen at $0^{\circ} \mathrm{C}$ was added a solution of $\mathrm{n}$-BuLi ( $1.70 \mathrm{~mL} .120 \mathrm{M}^{0} \%, 2.5 \mathrm{M}$ solution in THF) dropwise with a syringe. After $30 \mathrm{~min} \mathrm{CbzCl}\left(0.285 \mathrm{~mL} .120 \mathrm{M}^{\circ}\right.$ o $)$ was added and then the reaction misture was stirred for $60 \mathrm{~min}$ at the same temperature. quenched with saturated $\mathrm{NH}_{4} \mathrm{Cl}$ solution (20 $\mathrm{mL})$. and extracted with ether $(30 \mathrm{~mL} \times 3)$. The organic layer was dried. filtered. and concentrated to give the crude product, which was purified by flash column chromatography to give the cyclized product $2 \mathrm{a}\left(0.95 \mathrm{~g} .96^{\circ} \%\right.$ vield). oil: $R_{f}=0.8$ (ethyl acetate hexane 37): 'H NMR (300 MHz. CDCl 3 ) $87.39-7.33$ (m. 5H. Ar). 5.21 (s. $2 \mathrm{H} . \mathrm{OCH}_{2}$ ) .3 .37 (s. $3 \mathrm{H}$. $\mathrm{NCH}_{3}$ ). 3.05 (s. $2 \mathrm{H} . \mathrm{SCH}_{2}$ ). 1.34 (s. $6 \mathrm{H} .2 \mathrm{CH}_{3}$ ).

12. For benzyl $N$ - $\left(1\right.$-phenylethyl)carbamate, benzyl $N$-benzyl- $N^{\prime \prime}$ methylcarbamate, $x$-benzyloxycarbonyl- $X$ '-propylethylenediamine 5 and 1-benzyloxvearbonyl-3-methylpiperazine 6. see: (a) Kondo K.: Sekimoto. E.: Nakao. T.: Murakami. Y. Tetwhedron 2000. 56. 5843. For benzyl N-benzylcarbamate. see: (b) Keck. G. E.: Wager. T. T.: McHardy. S. F. Tetrahedron 1999. 55. 11755 . For tert-butyl $N$-benzy $1-N^{\prime}$-methylcarbamate and tert-butyl $N$-benzlcarbamate. see: (c) Alonso. E.: Ramon, D. J.: Yus. M. Tetrahedron 1997, 53. 14355. 